\title{
ANN Based Current Controller for Hybrid Electric Vehicles
}

\author{
Kavati.Nagendar, ${ }^{1, *}$, and V.Vijaya Rama Raju ${ }^{2}$ \\ ${ }^{1}$ PG Student, Department of EEE, GRIET, Hyderabad, India. \\ ${ }^{2}$ Associate Professor, Department of EEE, GRIET, Hyderabad, India.
}

\begin{abstract}
The use of Hybrid Electric Vehicles (HEVs) across the world is growing enormously every day. The single-phase bi-directional convertors are presented in this study for HEVs on-board charging(OBC). In HEVs, we use power electronics converters for the converting and inverting operations. Artificial Neural Network(ANN) is presented in this study for simple operation and high optimization approaches. ANN control technique regulates the system's THD and enhances charging system optimization, enables two-way power delivery that is from the grid to vehicle and the vehicle to grid. An ANN based current controller model that achieves fast-dynamic reaction and that improves grid current harmonic characteristics is proposed in this study. The system's THD is reduced by the ANN controller being suggested. The results prove the validity and feasibility of design and control technique of the proposed integrated charging system.
\end{abstract}

Keywords: DC-DC bi-directional converters (BDCs), Artificial Neural Network algorithms, Electric Vehicles.

\section{Introduction}

Hybrid Electric Vehicles (EVs) and Electric Vehicles (EVs) are generally the vehicles that must meet the standards for urban transportation emissions during the next 10 years. HEVs are a hybrid between traditional combustion engine vehicles and electric vehicles (EVs)[1], a compromised alternative that addresses issues such as air pollution, petroleum combustion, and limited driving range[2]. HEV [3] is made up of various components such as machines, gearbox, battery, charger, traction engine, and its driving inverter. A second power generator and its drive inverter are also included in system. The starter-generator system's goal is to start engine from a standstill and transform vehicle's kinetic energy into electric energy [4-5]. In this study, starter mechanism is modified to act as battery charger, rather of $\mathrm{OBC}$, which is found in most HEVs (OBC). As result, upgraded start-generator system employs two distinct modes. The first is a motor drive that acts as a typical starter-generator. The charging battery is the other. Because this integrated charging method substitutes traditional $\mathrm{OBC}$, it is possible toeliminate traditional OBC from HEVs. As a result, the redesigned circuit reduces the volume and weight of HEVs while also increasing power density. A feedback-based current control technology, such as proportional-integral controller, has emphasised the power converter's performance in recent decades[5-6]. The PI current controller achieves fine control results by translating time variable on synchronous frame into timevariable. Some of the flaws in this control strategy, however, are due to the controller's system parameter design. Furthermore, designing a controller for a sophisticated system is difficult. Model Predictive Current Control (MPCC) is introduced in this study as method for controlling 1-phase full-bridge inverter when integrated circuit is operating in battery charging mode. For high total harmonic distortion (THD) in output current, the typical MPCC produces eight separate voltage vectors because single phase two-level inverter only makes three distinct output voltages. THD in output current can be reduced by increasing sampling duration and reducing calculation time. Harmonic features of output current are limited and increased using an advanced MPCC method. Compared to typical feedbackbased control method, the MPCC methodology has a faster dynamic response time. Output current has superior harmonic characteristics when compared to MPCC's normal method. Simulation results confirm the accuracy of proposed integrated charging design and control strategy of the system. There are several industries that look to bidirectional DC-DC converters (BDCs) as energy sources to improve the transmission and distribution of energy. As a result of system losses, efficiency is reduced and circuit elements' lifespan is shortened. Deshalb sollten in order to avoid power loss, better control systems be implemented whenever possible. A bidirectional power flow's efficiency is crucial to obtaining high-quality electrical energy. To improve the efficiency of the converter, a variety of control mechanisms are currently being explored. One of these control approaches is the artificial neural network (ANN), which is based on a variety of algorithms. Vector support (SVM) and autonomous map (SOM) approaches are used in ANN to feed forward information (FF). They are divided into two 
categories, supervised and unsupervised. To determine the most efficient input voltage for the converter, various ways are utilised, and one of these techniques is an acceptable algorithm. ANNs are not often used in electronic equipment for power regulation, according to some study. Matlab simulates a single-phase Full-Bridge Isolated BDC with input voltages ranging from $100 \mathrm{~V}$ to $400 \mathrm{~V}$ and an output voltage of $160 \mathrm{~V}$. Parallel to the IGBTs, this type of converter also incorporates condensers, which help to improve the efficiency of the system. In supervised or uncontrolled learning, SOM, SVM, and FF identify the data set of the converter that has been taught to provide low error levels. In the third section, the ANN method is discussed, the optimal input voltage is found, and input voltage classification is displayed. This research presents a new method for forecasting adaptive dc connection voltage using the SOM algorithm. In this approach, artificial neural networks (ANNs) are utilised to forecast and adapt the reference dc connection voltage quickly. Further, the system will feature both supervised and unsupervised control options. In the performance analysis, both the proposed controllers and alternative control methods of ANN algorithms were examined. To conclude, MATLAB simulation software is used to verify whether or not the new control strategy has been effective.

\section{Starter-Generator Based Integrated Charging System.}

A standard HEV is composed of a generator, a driving inverter, a battery, and an OBC. Thus, higher power density is one of major significant obstacles to development of HEVs. This study discusses integrated circuit's battery charging and motor driving capabilities. As seen in Fig1, proposed circuit consists of two-level inverter, a generator, and seven power relays. The advantage is that starter-generator drive system's power rating enables charging of battery. When this system design is applied to traction motor circuit, the high power rating of traction motor circuit can be used to charge battery.

\section{A. Drive Mode Starter Generator}

The mode in which the starting generator is driven is depicted in Fig. 1. (a). In this mode, relay 06 is enabled to connect the battery to the three-phase inverter. DC link and battery share same electrical node, and battery powers three-phase inverter that drives starters. When relays 03 and 04 are active, inverter is able to supply generator set with three phase electricity. This mode is identical to oldest starter-generator, which drives or breaks vehicle using regenerative energy.

\section{B. Bi-Steer OBC Mode}

As illustrated in Fig. 1(b), integral circuit is modified to provide a single-phase, two-way OBC circuit. Grid filter reactor, full-bridge ac-dc converter, and battery comprise OBC method circuit. Relay 05 and 07 will be triggered in order to employ starter generator winding as filter reactor for DC-DC conversion. Then, the grid will be connected to full bridge conversion unit via relays 01 and 02 , which will be $\mathrm{ON}$. The corresponding induction equivalent of the filter is 1.5 times that of generator's single winding. On this $\mathrm{OBC}$ circuit, two alternate transmission statuses are provided. When power is delivered to the car from the grid, the battery is charged and the state is referred to as G2V mode. Rather than that, V2G mode uses the battery's energy as a standard energy storage device.

\section{ANN-BASED CONTROLLER.}

The ANN controller has two outputs one for voltage level control via the grid corrector and another for current control via the Buck/Boost conversion to maintain load current. Grid tension and DC-link tension control are used to control tension controlled system. As result, some parameters are estimated as critical inputs to controller. To begin, there is an error between DC- estimated link's voltage and established reference voltage. Calculated error is then communicated to ANN control unit by establishing corresponding shift angle. Second, from immediate grid voltage, direct and quadrature voltages are generated. Real voltage, in comparison to desired direct voltage, an error that specifies amount of modulation signal required between two as input to ANN controller for controlling DC/DC converter. Critical operating equations for bucking and boosting activities can be calculated by (1) to (4) for bucking and (5) to

(9) for boosting operations, respectively.

$$
\begin{aligned}
& V_{\text {EvBattery }}=V_{D C L i n k}-L_{0} \frac{d I_{\text {charging }}}{d t} \\
& I_{\text {charging }}=\frac{1}{L_{0}} \int_{0}^{T_{\text {on }}}\left(V_{D C L i n k}-V_{E v \text { Battery }}\right) \cdot d t \\
& V_{E v \text { Battery }}=L_{0} \frac{d I_{\text {charging }}}{d t} \\
& I_{\text {charging }}=\int_{T_{m n}}^{T_{\text {off }}}\left(-\frac{V_{E v B a t t e r y}}{L 0}\right) d t
\end{aligned}
$$




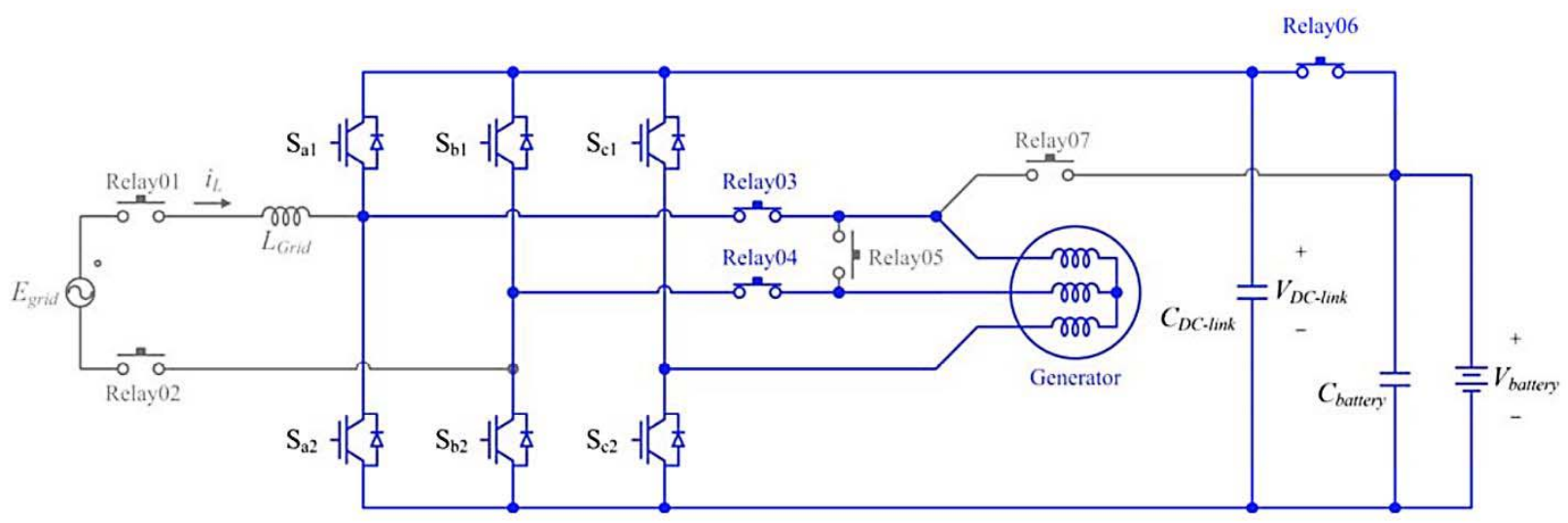

(a)

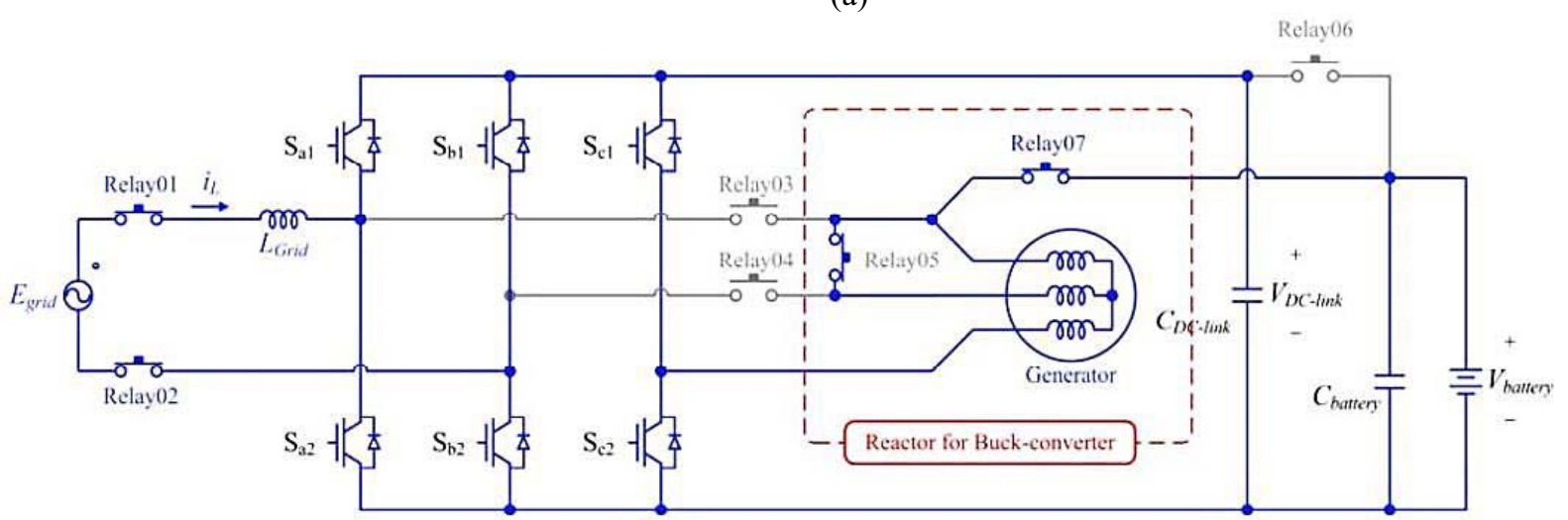

(b)

Fig. 1. Integrated charging system construction: (a) drive mode of the starter generator. (b) single-phase OBC mode.

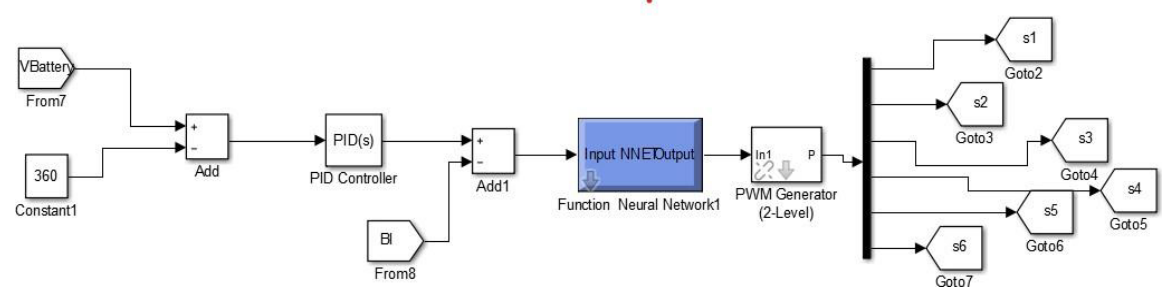

Fig.2 ANN controller block diagram

$$
\begin{aligned}
& V_{E v \text { Battery }}=L_{0} \frac{d I_{\text {charging }}}{d t} \\
& I_{\text {charging }}=\frac{1}{L_{0}} \int_{0}^{T_{\text {on }}}\left(V_{E v \text { Battery }}\right) \cdot d t \\
& -V_{\text {EvBattery }}+V_{L_{0}}=V_{D \text { CLink }} \\
& I_{\text {charging }}=\int_{T_{m n}}^{T_{o f f}}\left(V_{E v \text { Battery }+V_{D C L i n k}}\right) d t
\end{aligned}
$$

\footnotetext{
*Corresponding author: kavati.nagendar@gmail.com
}

(5) The current controlled loop establishes the working mode of two-way buckboost converter by utilising battery reference current. The calculated battery current inaccuracy is used to calculate the duty ratio of the power output of ANN control unit. The tariff ratio is communicated to PWM modulator, which modulates switching signal of IGBT. Low error between objective result and network reference is required for ANN training. This training is carried out in this study utilising a well-established technique based on Levenberge- Marquadt algorithm. For this challenge, device created here has two inputs and two outputs. The error equation for particular node is 
the kth neuron connected to the nth neuron of the previous layer (9). Equation illustrates summative error $\operatorname{Equ}(10)$.

$e_{j}=y_{j}-f\left(x_{i}, w_{k, n}^{p}\right)$

$E=\frac{1}{N} \sum_{l=1}^{n} e_{j}^{2}$

The algorithm for updating the weight of any object is given by:

$\gamma_{k+1}=\gamma_{k}-\beta_{k}^{-1} \delta_{k}$

Where $\gamma_{k}=w_{k, n}^{p} \delta_{k_{k}} \delta_{k}$ the parameters are LM Training results demonstrate a perfect fit with low errors for the ANN network.

\section{Results :}

\section{MPCC Method of controlling.}

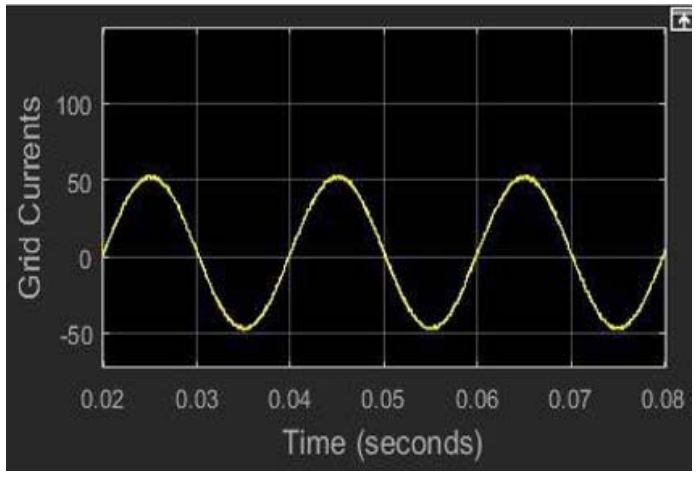

(a)

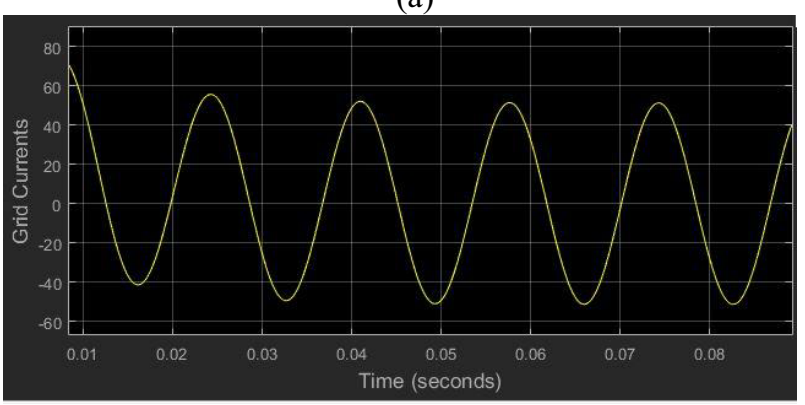

(b)

Fig. 3. MPCC method simulation results: (a) current conventional MPCC control method. (b) current MPCC control method

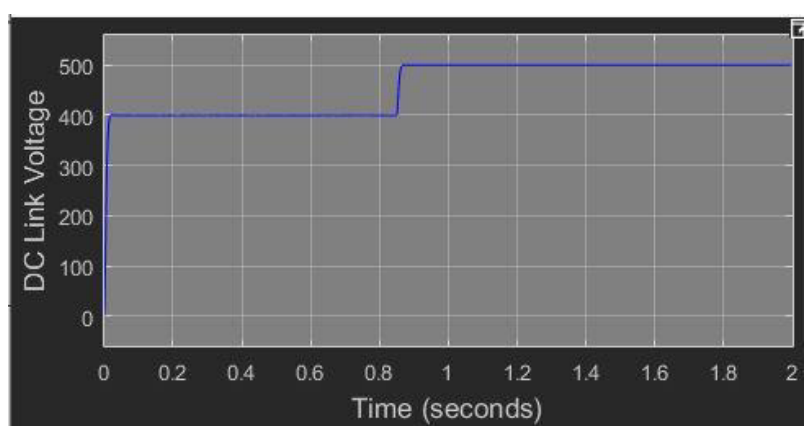

(a)

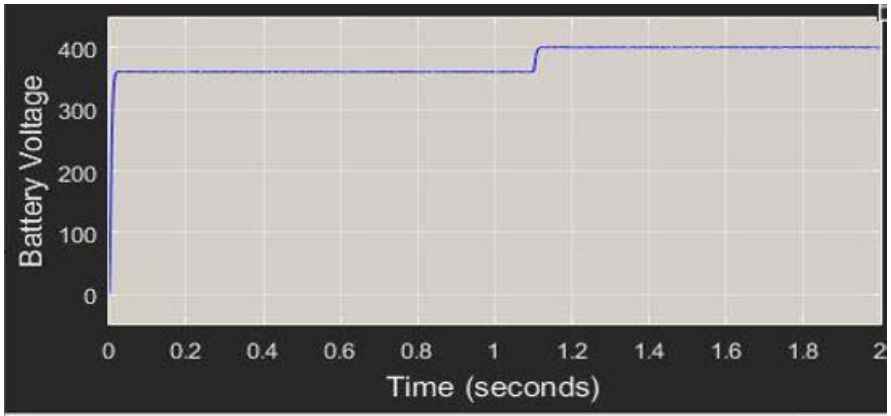

(b)

Fig.4. Integrated charging system simulation waveforms (a) voltage control DC-link (b) Battery voltage control
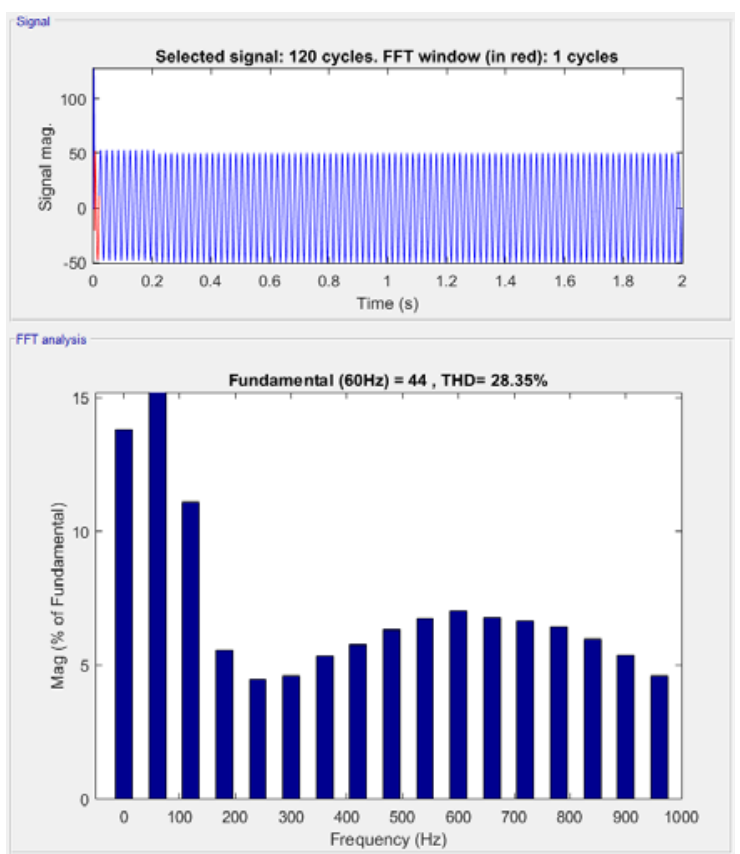

(a) 


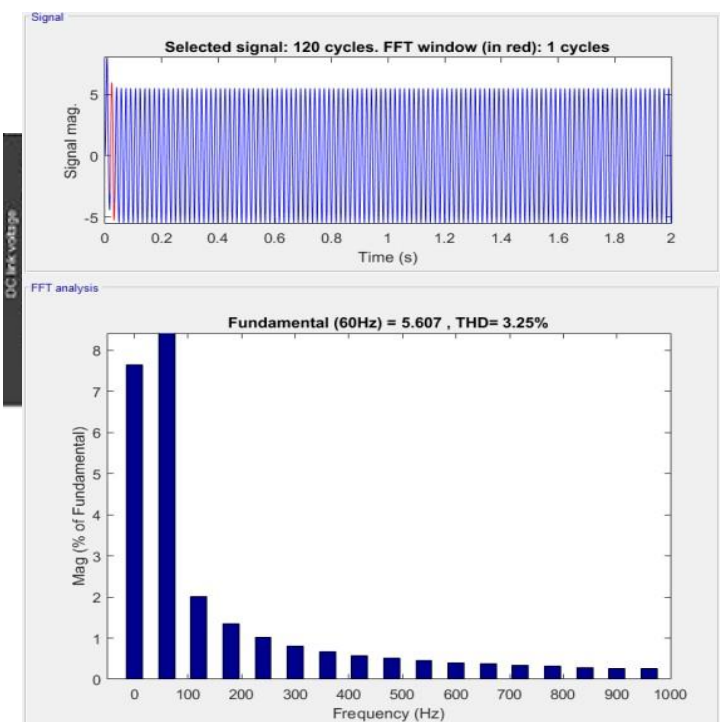

(b)

Fig.5. The simulation results shows current THD is $22.84 \%$ and $3.25 \%$ in the conventional MPCC method of control.

\section{Proposed ANN Controller :}

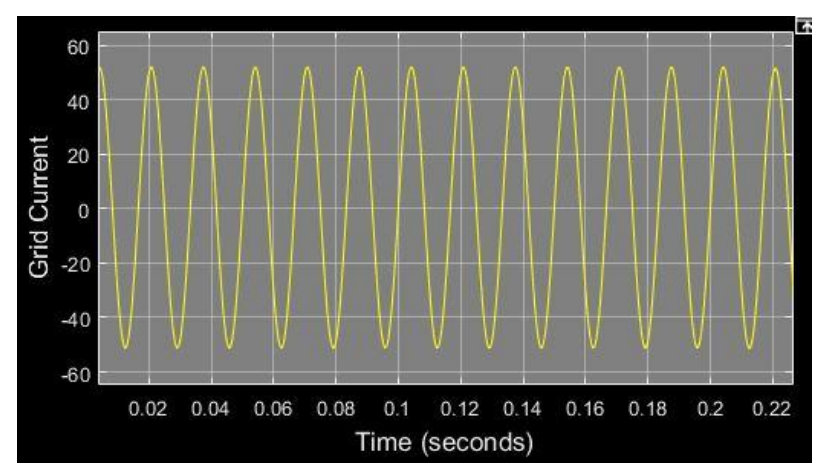

(a)

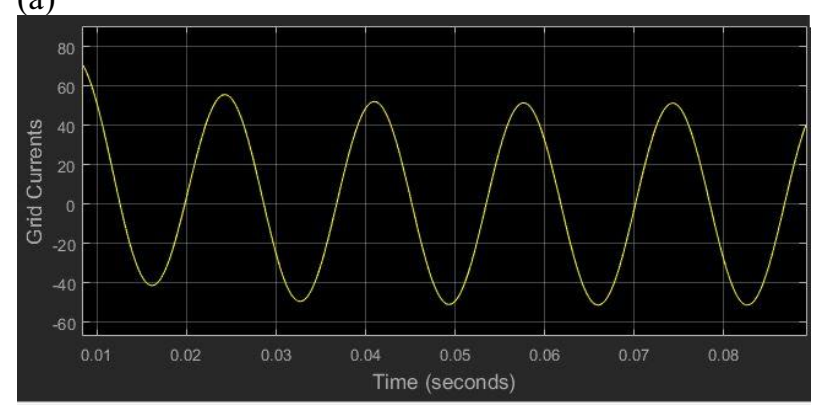

(b)

Fig.6.Grid currents (a) starter-generator ANN controlcurrent (b) OBC ANN control current monitoring. (a)

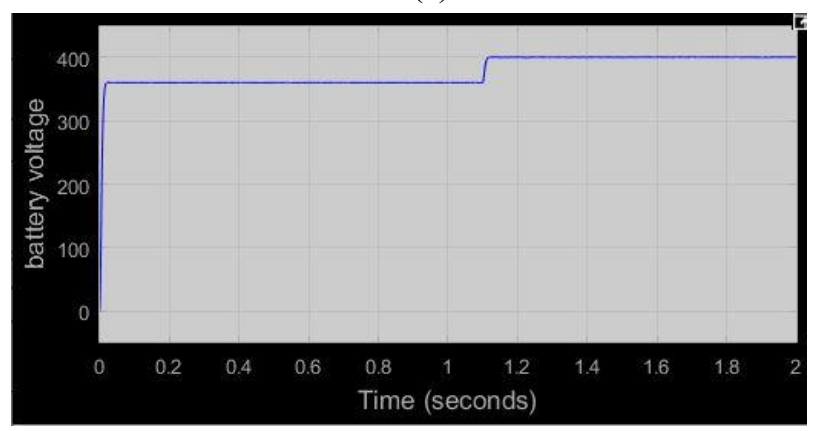

(b)

Fig.7. Simulation waveforms of the integrated charging system (a) control voltage of DC-link (b) Battery voltagecontroller

(a)

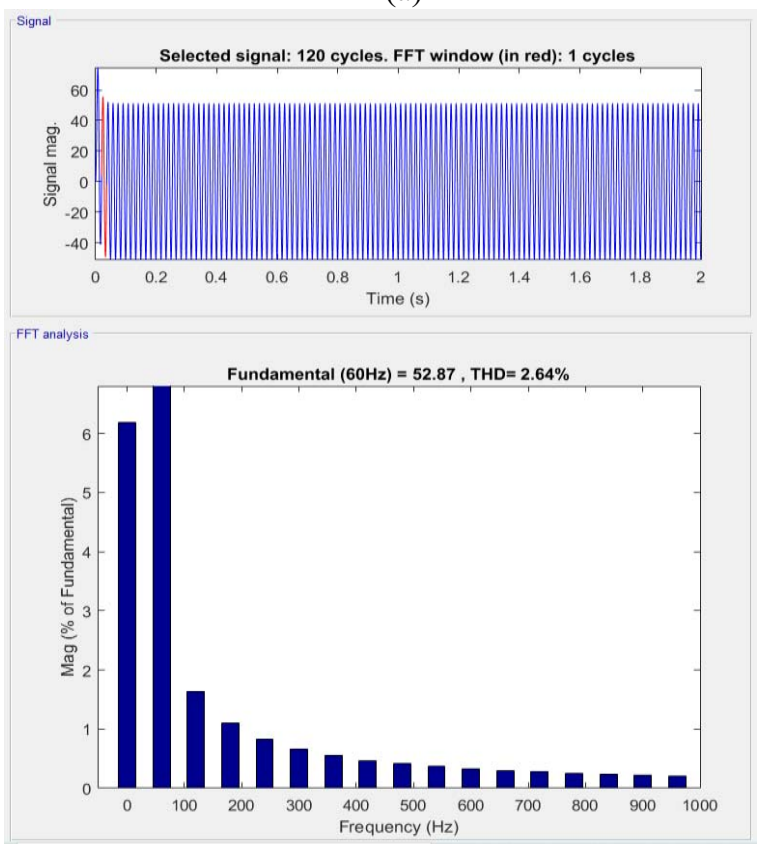




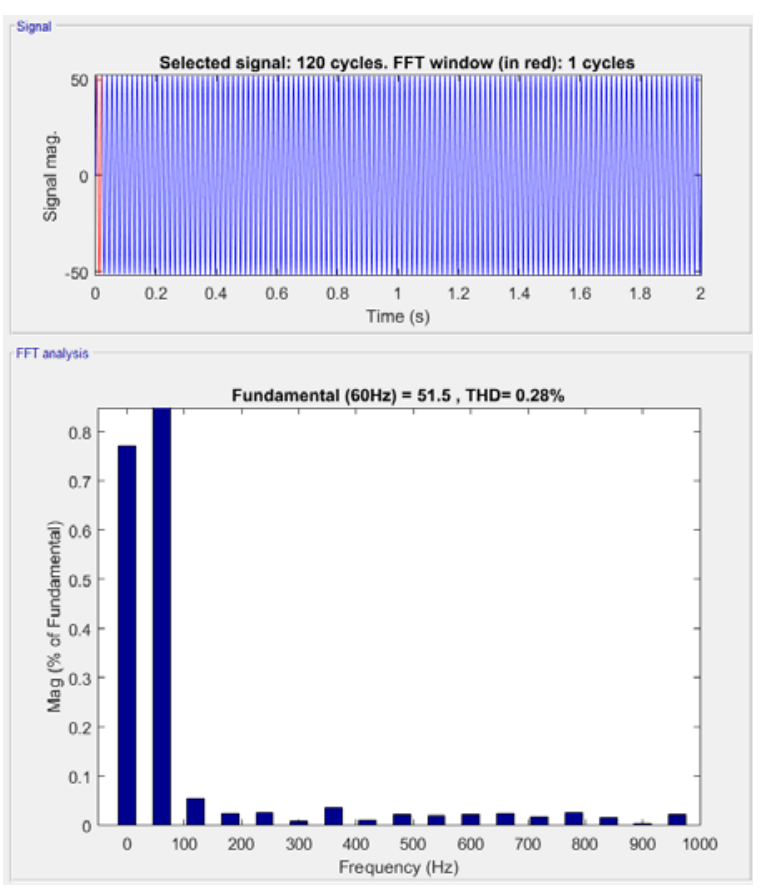

(b)

Fig.8. The simulation results shows the THD of grid- current is reduced as follows $2.64 \%$ and $0.28 \%$ respectively in two modes of operations by using ANN controller.

\section{Conclusion}

This paper introduces the ANN controller used for the, controlling of the bidirectional converter which reduces the THD of the Grid currents and the EV currents and to be improve in Power Quality of the System. The grid current regulation are supported by the ANN based controller. The power of reaction to counter the un-equilibrium generated by EV loads is collected from the DC connection capacitor. The charger is capable of changing the charge current via the ANN controller of several charging modes. ANN controller enables the two-way V2G charger to operate in different power rates. Performance of the ANN-based bidirectional charger is validated by the simulation results. Here, ANN-based technique is compatible and provides inexpensive and viable solution for high-power applications with any of the batteryspecific voltages and currents.

\section{References}

1. Ho-Sung Kang, Seok-Min Kim, and Kyo-Beum Lee IEEE Applied Power Electronics Conference and Exposition (APEC).DOI: 10.1109/APEC.2019.8722297 (2019)

2. Rakesh Kumar Phanden, Ruchika Gupta, Srinivasa Rao Gorrepati, Pranav Patel, Lalit Sharma. Materials Today: Proceedings, (2020)

3. Ho-Sung Kang, Seok-Min Kim, Kyo-Beum Lee. IEEE Applied Power Electronics Conference and Exposition (APEC), (2019)

4. Shubham Sundeep, Bhim Singh, IEEE Transactions on Power Electronics, (2017)

5. Varun Malyala, Phaneendra Babu Bobba. IEEE 1st International Conference on Power Electronics,
Intelligent Control and Energy Systems (ICPEICES), (2016)

6. Anil Kumar Rajagiri, Sandhya Rani MN, Syed Sarfaraz Nawaz, Suresh Kumar T, E3S Web of Conferences, (2019)

7. Tian-Hua Liu, Pei-Heng Yi, Jui-Ling Chen, IECON 2014 - 40th Annual Conference of the IEEE Industrial Electronics Society, (2014)

8. Osman Kukrer, Hasan Komurcugil, Ramon Guzman, Luis Garcia de Vicuna, IEEE Transactions on Industrial Electronics, (2021)

9. Mahalle, G., Salunke, O., Kotkunde, N., Gupta, A.K., Singh, S.K. Journal of Materials Research and Technology, 8 (2), pp. 2130-2140,(2019) 